Fecha de recepción: 1 de marzo de 2021

Sugerencia de citación: Galindo, J. (2021). Empresas familiares, estrategias y persistencia: los franceses y su importancia en la industrialización de México. tiempo\&economía, 8(2), 75-105. https://doi.org/10.21789/24222704.1765
DOI:

https://doi.org/10.21789/24222704.1765

\title{
Empresas familiares, estrategias y persistencia: los franceses y su importancia en la industrialización de México
}

\author{
Family Businesses, Strategies, and \\ Persistence: French People and their \\ Importance in the Industrialization of \\ Mexico \\ José Galindo \\ Instituto de Investigaciones Histórico-Sociales, \\ Universidad Veracruzana, Xalapa, México \\ https://orcid.org/0000-0002-7645-053X \\ jgalindor@yahoo.com
}

\section{Resumen}

En este artículo se reflexiona sobre las estrategias generales e individuales de empresarios franceses de origen barcelonnette en México, así como sobre las particularidades y las relaciones que distintas generaciones de estos empresarios establecieron para el éxito de sus negocios, en aquellos casos donde esto ocurrió. El análisis también muestra el contexto en que sus actividades empresariales lograron expandirse, aun en un país carente de instituciones formales sólidas. Esta situación los llevó a emplear 
estrategias que incluyeron relaciones cercanas y asociación con diversos regímenes políticos del país.

Palabras clave: empresas familiares, capitalismo, estrategias, redes, México, historia económica.

CódigosJEL: D20, F23, H32.

\section{ABSTRACT}

This article reflects on the general and individual strategies of French entrepreneurs of Barcelonnette origin in Mexico, as well as on the particularities and relationships that different generations of these entrepreneurs established for the success of their businesses, in the cases where this occurred. Furthermore, the analysis shows the context in which their businesses expanded, despite being in a country that lacked solid formal institutions. Such institutional weakness led them to deploy strategies that included close relationships and association with various political regimes in Mexico.

Keywords: Family businesses, capitalism, business strategies, networks, Mexico, economic history.

JELCodes: D20, F23, H32.

\section{INTRODUCCIÓN}

La comunidad de inmigrantes de origen francés llamados barcelonnettes representa un claro ejemplo de red de empresarios étnicos, lo que significa que su red de negocios compartió un trasfondo nacional común y experiencias de migración. Esta situación facilitó su éxito en México, en medio de un contexto de instituciones formales débiles. La importancia de estudiar a los empresarios de origen barcelonnette en este país radica en que ello permite identificar las estrategias utilizadas, las redes que construyeron y las estructuras con las que se relacionaron, así como el contexto en el que se desarrollaron sus negocios. Así mismo, este análisis permite estudiar la manera en que estos empresarios enfrentaron diferentes procesos históricos durante las distintas etapas del desarrollo de sus negocios, lo cual los llevó a construir relaciones diferentes durante gran parte del siglo XIX con los nuevos empresarios y gobiernos que surgieron a partir de la Revolución de 
1910-1920, llevando a algunos barcelonnettes a perdurar dentro de la élite económica del país hasta nuestros días. Esta investigación también brinda a los lectores una aproximación al capitalismo de amigos, o de vínculos estrechos entre el gobierno y empresarios, y otros elementos que apoyaron el éxito de esta comunidad francesa en México. ${ }^{1}$

\section{CONTEXTO: LLEGADA DE LOS BARCELONNETTES A MÉXICO}

La migración hacia México de individuos provenientes de Barcelonnette (Francia) inició a partir del primer tercio del siglo XIX a través del Atlántico, motivada principalmente por circunstancias socioeconómicas y políticas que incluyen los efectos de la Revolución Industrial Europea. México ofreció a estos migrantes oportunidades específicas que eventualmente permitieron su éxito, incluidos argumentos raciales y culturales (construcciones imaginarias basadas en nociones de "occidente", de lo "europeo" y lo "moderno") que fueron importantes en el desarrollo y la transformación de las naciones de América Latina durante el siglo XIX. Se creía entonces que los inmigrantes europeos podían ayudar a construir naciones similares a las de su lugar de origen y además "mejorar la raza".

Los inmigrantes franceses no fueron, por lo tanto, un obstáculo para los gobiernos y sus políticas. Por el contrario, los mismos gobiernos vieron a estas personas como un potencial económico y político, aliados en la "europeización" de la sociedad mexicana y la modernización de la economía, como sucedió durante el Porfiriato en México (1876-1911). En ese período, los inmigrantes disfrutaron mayores privilegios y concesiones, algunas de las cuales fueron establecidas en leyes específicas que los favorecieron; por ejemplo, la ley de naturalización de bienes alienados promulgada en 1886, por la que extranjeros que adquirieran propiedades en territorio mexicano podían ser naturalizados como tales, con la condición de renunciar a su nacionalidad anterior (Echanove, 1974, p. 35). Por su parte, casi toda la sociedad mexicana prefería migración extranjera compuesta de católicos de origen latino, especialmente españoles, franceses, belgas e italianos, "por ser más fácilmente

Para un estudio profundo del tema, consultar la obra de José Galindo titulada "Ethnic Entrepreneurs, Crony Capitalism, and the Making of the Franco-Mexican Elite". University of Alabama Press, primera edición, 2021. 
asimilados", aunque en la práctica la migración extranjera no se limitó a estas nacionalidades (Kenny et al., 1979, p. 30), como se observa en la figura 1.

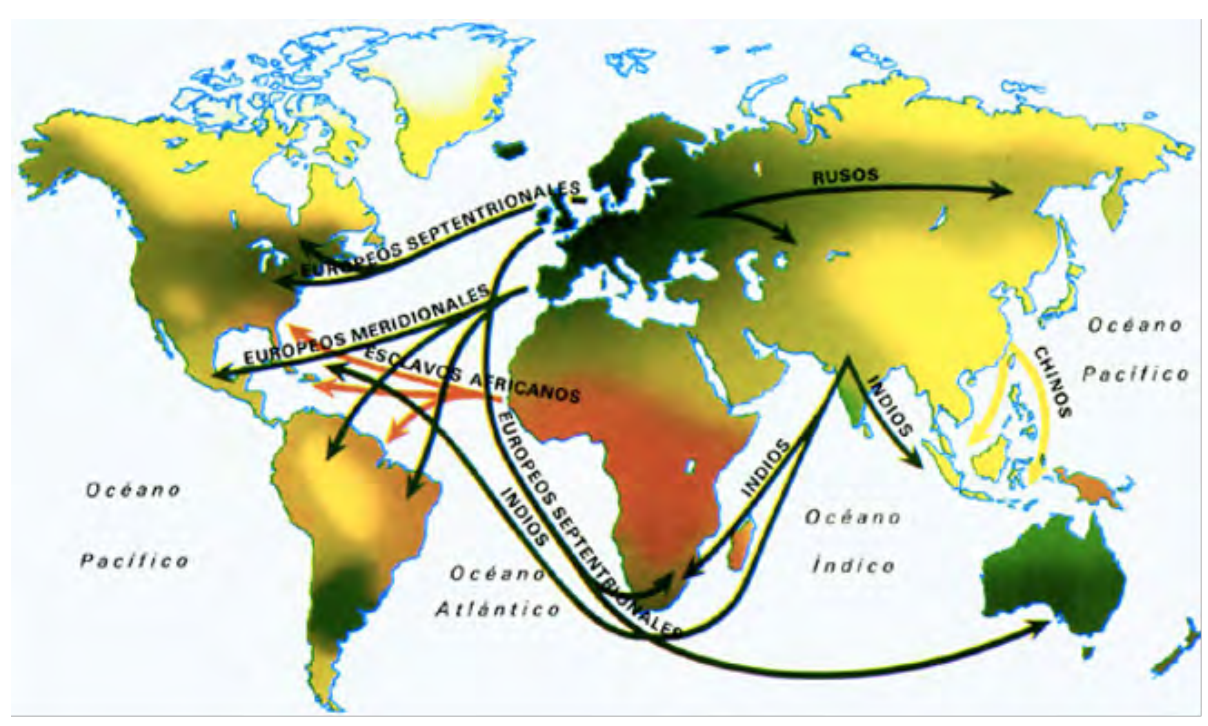

Figura 1. Mapa ilustrativo de algunas de rutas migración durante siglo XIX

Fuente: Grupo Eleuterio Quintanilla (2021).

\section{GENERACIONES DE BARCELONNETTES EN MÉXICO Y ESTRATEGIAS EMPRESARIALES}

El proceso migratorio en cadena de Barcelonnette a México comenzó en 1821 y continuó a lo largo de casi todo el siglo XIX y la primera década del siglo XX. La historia de inmigración del grupo viene como resultado de muchos desafíos que experimentaron en su Francia natal, como el declive de los textiles hechos a mano debido a una fuerte competencia entre artículos, históricamente fabricados por familias, y las heladas invernales que impidieron la producción de la industria textil y otros sectores, entre otros. Esta situación limitó las ventas ambulantes, principal actividad económica en los Alpes bajos.

Ante ese escenario, la comunidad francesa de Barcelonnette, originalmente pobre, buscó migrar en masa hacia México. Las características específicas de la organización interna del grupo en su lugar de trabajo, una vez establecidos en América, los valores que compartían y las redes de negocios que crearon - que incluían a políticos mexicanos en ciertos sectores - son algunos de los aspectos que permitieron a una parte de ellos hacerse ricos y eventualmente penetrar en la élite económica mexicana. 
Para su estudio, el autor divide esta historia de migración en tres generaciones, diferenciando sus actividades, estrategias y redes establecidas, como se explica a continuación.

\section{Primera generación: el surgimiento de cajones de ropa barcelonnettes}

Todo comenzó en 1821, cuando los hermanos Arnaud partieron hacia América después de cerrar su taller de seda en Jaussiers, un pueblo cerca de Barcelonnette. De acuerdo con Béraud (2008), se desconocen los motivos por los que estos hermanos llegaron a México, pero se sabe que Jacques, el mayor de ellos, se hallaba en 1805 en Luisiana (Estados Unidos), donde emprendió un negocio. En ese época existía un intenso comercio entre Nueva España y Nueva Orleans, por lo que quizás sea esto lo que los trajo a México (Béraud, 2008, p. 250).

Los hermanos Arnaud abrieron su primera tienda de novedades, Ilamada Las Siete Puertas, en la Ciudad de México en 1829. Este negocio no fue muy próspero pero sirvió como semilla para otros emprendimientos. Por ejemplo, algunos barcelonnettes que habían trabajado en Las Siete Puertas, como Eugène Caire y Alphonse Jauffred, se asociaron con Gabriel Derbez y abrieron una tienda similar en 1838, conocida como Las Fábricas de Francia, la cual fue más exitosa. Los resultados positivos de esta tienda le permitieron a Caire y Jauffred regresar a Francia en 1845 siendo ricos. Algunos autores mencionan que cada uno de los socios de esta tienda había obtenido ganancias por 50.000 pesos de la época (equivalentes a 200.000 francos de oro) previo a su regreso a Francia, cifra que representaba una fortuna en su localidad de origen. La noticia de la riqueza generada creó una importante corriente de migración de la región de Barcelonnette y sus alrededores hacia México.

Las tiendas de esta primera generación, que eran sencillas habitaciones en la planta baja de antiguas casas coloniales, eran conocidas como cajones de ropa. Estas tenían una organización muy estricta y disciplinada, cuya jerarquía estaba dividida en jefes (miembros fundadores de origen barcelonnette que codirigían las tiendas), empleados asalariados con derecho a utilidades y aprendices en entrenamiento. Los empleados de estas tiendas eran jóvenes con un buen grado de preparación escolar (Gouy, 1980, pp. 2138). Además de que su vida se caracterizaba por la austeridad y el trabajo duro, los inmigrantes de origen barcelonnette compartieron un entorno que los mantuvo aislados de la realidad mexicana y totalmente dependientes de 
sus empleadores. La oportunidad de ser contratado en México por algún compatriota generó una cohesión étnica que permitió que cerca de 2.000 jóvenes, desde mediados del siglo XIX hasta mediados del siglo XX, llegaran a trabajar a México (Gómez-Galvarriato, 2008, p. 194). Esta migración en masa, sin embargo, tuvo características específicas por generaciones, lo que nos permite hacer esta distinción en el presente análisis.

Una vez contratados, los inmigrantes trabajaban al menos un año en empleos simples por salarios extremadamente bajos. Cuando tenían suficiente comprensión del español y las operaciones de los negocios -y tras obtener el respeto de sus jefes - podían servir detrás del mostrador y ser promovidos después de un tiempo a posiciones como contadores o agentes viajeros. Algunos llegaron a ser socios comerciales o establecer sus propios negocios. De hecho, después de su llegada a México, tomaba a los inmigrantes barcelonnettes un promedio de cuatro a seis años para iniciar sus propios negocios, que eran normalmente pequeños (Galán, 2010, p. 73). Con suerte, guardar ganancias después de unas pocas décadas les permitiría regresar a Francia y casarse (Gómez-Galvarriato, 2008, pp. 195-196), tras lo cual la gestión de sus negocios era transferida a compatriotas o familiares, mientras los dueños conservaban la propiedad desde Francia.

En este escenario, ¿qué factores contribuyeron a que muchos de estos inmigrantes regresaran siendo ricos a Francia o a que fundaran más tiendas en México? Lo anterior podría ser explicado por el hecho de que los barcelonnettes crearon fuertes redes entre ellos mismos, originando una cohesión étnica que permitió el establecimiento de tiendas por medio de socios y de contratos a largo plazo, desarrollando así una red en la que "los abastecedores ofrecían buenas facilidades de pagos y ayudaban a ampliar el negocio o inaugurar nuevas casas comerciales" (Gouy, 1980, p. 60). A esto hay que sumar que también gozaron de la confianza de sus proveedores al adquirir una reputación de honestidad y de buenos pagadores, hecho que les permitió obtener suficientes existencias iniciales sin contar con recursos para adquirirlas, en principio.

Así, para mediados del siglo XIX los Barcelonnettes habían establecido nueve casas de venta en México. Cinco de estas se encontraban en Ciudad de México y el resto en las ciudades capitales de los estados de México, Zacatecas, Puebla y Jalisco (Meyer, 1980, p. 28), dedicándose a la venta de telas comunes, principalmente para producir ropa de cama y ropa interior. A pesar de su expansión, el comercio minorista y de intermediarios era en 
gran medida controlado por españoles y mexicanos. En general, los productos en oferta eran muy poco diversificados, de baja calidad y se comercializaban en establecimientos pequeños.

Entre 1850 y 1864, el número de tiendas de tela propiedad de barcelonnettes aumentó de 5 a 12 en la Ciudad de México, con alrededor de 20 tiendas adicionales en otros estados del país. Para 1864, los registros señalan alrededor de 45 negocios barcelonnettes en México, 19 en la capital y 25 en provincia, empleando a cerca de 400 barcelonnettes (Béraud, 2008, p. 253). Sin embargo, durante esta primera generación, no se debe exagerar la importancia de sus tiendas, debido a que para mediados de 1860 sus cajones de ropa seguían siendo simples tiendas minoristas que vendían tejidos a las clases más bajas.

En cuanto a la formación de la red original de barcelonnettes y los elementos fundamentales por destacar durante esta primera generación, la creación de una red étnica cerrada les permitió a estos empresarios obtener ventajas iniciales en un país en el que algunas instituciones aún no ofrecían infraestructura adecuada para garantizar, por ejemplo, los contratos de largo plazo o los créditos formales para la inversión en infraestructura física o la compra de inventarios. Es decir, en el caso de la banca en México, el proceso de captación de recursos y otorgamiento de créditos para mediados del siglo XIX era todavía un mecanismo mayormente informal. En este sentido, la red inicial cerrada barcelonnette garantizó la disponibilidad de un sistema crediticio interno que aseguraba las condiciones de los préstamos realizados entre ellos mismos para fundar nuevas casas comerciales, los contratos de largo plazo entre ellos y con otros agentes, y la posibilidad de acceder a una oferta laboral capacitada y homogénea. Así mismo, las prácticas estandarizadas y estrictas en sus lugares de trabajo les otorgaron una buena reputación hacia el exterior, lo cual favoreció la confianza por parte de sus proveedores mayoristas de otras nacionalidades, quienes les proporcionaron condiciones de crédito excepcionales por fuera de un sistema bancario formal.

\section{Segunda generación: el surgimiento de grandes consorcios}

Se puede decir que aunque la migración proveniente de Barcelonnette no se detuvo desde el primer tercio del siglo XIX, a raíz de la intervención francesa a México, en los años 1860, surgió un corte generacional con cambios pronunciados en los negocios barcelonnettes. Este hecho, además de haber creado un apoyo sustancial para estos empresarios, cambió sus 
estrategias de negocio. De entrada, los barcelonnettes no se sintieron identificados con el emperador Maximiliano, aunque sí resultaron beneficiados por su gobierno, tras la creación, en 1863, de una ruta marítima entre St. Nazaire, ciudad en la costa occidental de Francia, y Veracruz, que fue complementada con la inauguración de una línea de ferrocarril que conectó la costa de Veracruz con la Ciudad de México, en 1873. El efecto de esto fue que, a partir de 1863, los franceses eliminaron gradualmente las casas mayoristas inglesas, alemanas y españolas en México, comprando las mercancías directamente en París y Manchester. De 80 casas de importación alemanas en 1870, dos tercios habían desaparecido para 1889. La última casa de tela alemana establecida en México cerró en 1892 (D’Anglade, 2012, p. 133), marcando así el inicio del verdadero éxito de la colonia barcelonnette en México.

La fase de acumulación de capital por parte de los barcelonnettes en México comenzó también durante la década de 1870. Estos comerciantes empezaron a utilizar intermediarios franceses, y algunos de ellos establecieron sus propias compañías para obtener productos directamente desde Europa, cambiando además la estructura de sus tiendas, que pasaron de ser cajones de ropa a convertirse en tiendas por departamentos; algunos incluso abrieron oficinas en Inglaterra y Francia para gestionar la exportación de productos a México. Para principios de la década de 1890 los franceses poseían 150 casas de tela, de las cuales 30 eran mayoristas y 118 pertenecían a inmigrantes barcelonnettes. Para 1910, año que representa el corte de la segunda generación, el número había llegado a 200, siendo 150 de ellas propiedad de barcelonnettes (Meyer, 1980, p. 30). Además, productos de alta calidad eran importados y vendidos en tiendas de barcelonnettes, siendo el principal objetivo satisfacer los gustos de una clientela acaudala y sofisticada. La importación no ocurrió con los artículos estándar, para los cuales la industria mexicana era barata y suficiente. Sin embargo, para ese momento la propiedad de la industria manufacturera mexicana estaba en manos de ciudadanos mexicanos y españoles, realidad que cambiaría en los años siguientes.

Entre 1870 y 1880 las actividades económicas de los barcelonnettes estaban centradas en el comercio y la consolidación de la distribución de ropa, aunque estos comenzaron a aventurarse en la industria textil - con el objetivo de controlar la producción-y en actividades financieras. Como mayoristas, los barcelonnettes se enfrentaron con la necesidad de proporcionar 
crédito a sus clientes con el fin de facilitar sus compras. Ofrecer condiciones de crédito a los minoristas era necesario a inicios de la década de 1880 , pues, como se mencionó anteriormente, en México no existía más que un rudimentario sistema bancario. Como resultado, los barcelonnettes continuaron compensando la ausencia de un sistema bancario formal a través de la creación de redes informales de crédito, las cuales crecieron al ritmo de sus negocios. Este sistema informal influenciaría el desarrollo del esquema formal en los años posteriores, en el que los franceses se convertirían eventualmente en sus principales propietarios.

A comienzos del Porfiriato, ante el estancamiento económico y el desorden político existente, el presidente Porfirio Díaz apoyó la creación de instituciones financieras para proporcionar recursos financieros destinados al gobierno. Los franceses fueron favorecidos por esta iniciativa, dando lugar en 1881 a la entrada de bancos franceses en el sistema bancario formal de México. Así, Edouard Noetzlin obtuvo una concesión y creó el Banco Nacional Mexicano (BNM), soportado principalmente con capital francés y mexicano (8 millones de pesos de la época). Poco después de la creación del BNM, en 1882, se fundó el Banco Mercantil Mexicano (BMM). Ambos bancos se fusionaron en 1884, dando origen al Banco Nacional de México (Banamex) (Bátiz, 2005, p. 96).

El primer barcelonnette en invertir en un banco mexicano fue Sébastian Robert, quien invirtió una pequeña cantidad de dinero en el BNM (Galán, 2010 , p. 120). La importancia del capital francés en el sector bancario en México creció con el paso del tiempo. Para 1910, 70 \% de los 20 millones de pesos del capital de Banamex pertenecía a ciudadanos de origen francés (Meyer, 1980, p. 35). Dado que no se pudieron establecer nuevos bancos de emisiones tras el anuncio, en 1884, de una nueva ley de comercio por parte del Congreso en, Banamex disfrutó un monopolio garantizado y se convirtió en el banco mexicano más poderoso. Para 1896, esta entidad controlaba más del $60 \%$ del capital bancario en México. En la práctica, esto significa que "el Estado renunció a crear un sistema bancario público como el de Inglaterra o Francia, para confiar a Banamex privilegios que no solo lo hicieron un cuasimonopolio privado, sino prácticamente el único árbitro en las operaciones financieras en el país" (D’Anglade, 2012, p. 218).

Los barcelonnettes dejaron de ser solo comerciantes para convertirse en comerciantes-financieros, invirtiendo masivamente en el segundo banco más importante del país en aquella época, el Banco de Londres y México 
(BLM), con el propósito de tomar control sobre este. El BLM era un descendiente directo del Banco de Londres, México y Sudamérica, siendo renombrado en 1889. Esta entidad bancaria se centró mayormente en actividades económicas como la inversión privada, en lugar de estar involucrado en la financiación pública. A principios de 1896, un número de barcelonnettes invirtieron fuertemente en el BLM, cuyo capital inicial fue de $\$ 1.500 .000{ }^{2}$ Este ascendió en 1891 a 5 millones, en 1896 a 10 millones, y en 1899 a 15 millones. Así mismo, la mesa directiva del banco incrementó de 5 a 12 socios (Canudas, 2005, p. 953), siendo varios de ellos dueños y socios de las principales tiendas y negocios barcelonnettes, como Joseph Ollivier, León Signoret, León Honnorat, los hermanos Tron — quienes crearon el Palacio de Hierro, una famosa tienda departamental aún en operación-y Alphonse Michel, socio director de Puerto de Liverpool, la única tienda departamental fundada y controlada hasta nuestros días por una familia de origen barcelonnette. De otro lado, el capital del BLM también contó con la participación de socios españoles e ingleses.

Para 1899, los barcelonnettes habían tomado casi por completo el control del BLM, entidad que participó de manera importante en las actividades de sus socios, financiando grandes consorcios industriales textiles también formados por barcelonnettes, como CIDOSA y CIVSA, de los cuales se hablará más adelante. El BLM igualmente financió las más grandes tiendas departamentales, como el Palacio de Hierro, el Centro Mercantil y el Puerto de Veracruz, así como actividades mineras, agrícolas y otros proyectos manufactureros, como fábricas de cerveza y compañías de cigarros.

Los franceses participaron también en otros bancos, como el Banco Central Mexicano, el cual fue una entidad de activos fijos, es decir, establecida para financiar bienes raíces, agricultura, minería e industrias; aunque estas últimas en menor proporción (Meyer, 1980, p. 35). El $60 \%$ del capital de esta entidad llegó a ser de origen francés, tras un crecimiento de 18 a 30 millones de pesos sobre el total del capital del banco. Tras su creación, en marzo de 1897, Sébastien Robert se volvió un importante accionista del Banco Central Mexicano.

Los barcelonnettes también participaron en otros proyectos bancarios, como La Sociedad Financiera para la industria en México (SFIM), creada en 1898, la cual se convirtió en un intermediario importante para obtener fondos en Europa. En 1909, se fundó la Compañía Bancaria de París y México (CBPM),

2 Las cifras expresadas en este documento corresponden a pesos mexicanos de la época. 
con una suma importante de capital de 10 millones de pesos (Notaría Público 5 Cd. de México, 1909; pp. 1-18), de los cuales la mitad provenía de barcelonnettes residentes en México (Notaría Público 5 Cd. de México, 1909; pp.118). Para su funcionamiento, una consultoría y un comité de vigilancia fueron creados en Francia. La CBPM resolvió los problemas de liquidez de sus propios dueños, concentrándose en operaciones a corto plazo. ${ }^{3}$

Es importante mencionar que aunque el sector bancario mexicano creció durante esos años, para 1910 todavía estaba limitado a menos de 20 empresas (Haber, 1989, pp. 64-65). De la misma manera, las regulaciones bancarias estaban limitadas por los intereses de los socios del sector, los cuales, esencialmente, debían ser cumplidos. Esta fue una característica distintiva de la manera de hacer negocios en México y gran parte de Latinoamérica durante la etapa inicial del desarrollo industrial de la región, es decir, la construcción del aparato legal en favor de intereses particulares, siendo difícil de controlar a lo largo de los años, incluso en el presente. En la sección sobre capitalismo de amigos estudiaremos a profundidad este fenómeno.

La caída del precio de la plata después de 1884 y el aumento de la demanda de textiles nacionales obligó a que las tarifas proteccionistas fueran aumentadas constantemente al final de la década de 1880, lo cual hizo que importar textiles a México fuera más costoso. Una de las consecuencias del proteccionismo - y una considerable devaluación del peso mexicano- fue que los importadores textiles (como los barcelonnettes) se vieran obligados a sustituir parte de la producción que habían estado importando desde Europa por textiles de origen nacional. Como resultado, estos empresarios también incursionaron en la adquisición de fábricas textiles previamente establecidas en México y en la inversión en proyectos industriales, que incluyó la fundación de nuevas fábricas textiles con instalaciones modernas; por ejemplo, la creación en 1889 de la Compañía Industrial de Orizaba, S.A. (CIDOSA). Así, a través de sociedades anónimas, se originó la asociación de tiendas comerciales fundadas por familias, sobre todo barcelonnettes, con fábricas grandes y modernas. Tal estrategia permitió que estos ciudadanos franceses obtuvieran ganancias monopólicas, controlando gran parte de la producción y distribución en el país (Gómez-Galvarriato, 2008, p. 207). Con ello, los barcelonnettes pasaron en poco tiempo de ser minoristas a consolidarse como mayoristas, banqueros e industriales.

3 Archivo Histórico Banamex, Compañía Bancaria de París y México, Informes de Asamblea General. 
Sumado a lo anterior, estos empresarios hicieron otras inversiones importantes en la industria textil en la década de 1890, como se detalla a continuación:

- Compañía Industrial de San Antonio Abad (CISAASA), fundada en 1892, manejó las fábricas Miraflores y La Colmena en el estado de México, así como la fábrica San Antonio Abad al sur de la capital.

- Compañía Industrial de Atlixco (CIASA), fundada en 1899, que tenía una de las fábricas más grandes del país, el Molino Metepec.

- Compañía Industrial Veracruzana S.A. (CIVSA), fundada en 1896. CIVSA construyó otra enorme fábrica, capaz de competir con Río Blanco: Santa Rosa, fundada en 1898.

En 1907, CIDOSA, CIVSA, CISAASA y CIASA representaban $35 \%$ del total de la industria textil mexicana del algodón.

Además, los barcelonnettes expandieron sus actividades a la producción de textiles de lana y otros sectores manufactureros. El favorable ambiente económico después de 1893, combinado con la presencia de barcelonnettes en el sistema bancario, contribuyó a la diversificación de las actividades económicas urbanas. ${ }^{4}$ Algunos barcelonnettes tuvieron también acceso a líneas de crédito sustanciales en Europa que les permitieron incrementar sus niveles de inversión. Algunas de sus fábricas de lana textil con inversión francesa incluían la fábrica de San Idelfonso, donde CIVSA y CIDOSA participaron, y La Victoria S.A.; esta última bajo el control de un grupo de empresarios vasco-asturianos en conjunto con el barcelonnette Augustín Garcin. La fábrica de Santa Teresa, en Ciudad de México, también fue una importante productora de textiles de lana.

La producción de papel también llegó a ser un destacado sector manufacturero. Las compañías San Rafael y Anexas fueron abiertas a mediados de la década de 1890 por un grupo de barcelonnettes y Thomas Braniff, un acaudalado inversionista estadounidense, quien también participó en CIDOSA. Estas compañías establecieron un monopolio en la producción de papel en México (D'Anglade, 2012, pp. 306-307). Otras grandes empresas con amplias inversiones de capital barcelonnette incluyeron la fábrica de cigarros El Buen Tono, Clemente Jacques, fábrica de alimentos en conserva aún en funcionamiento, empresas de cristalería, como Calpulalpan, y empresas de dinamitas 
Tabla 1. Inversión extranjera en México en 1910 (países y sectores)* y explosivos, como la Compañía Nacional Mexicana de Dinamita y Explosivos, entre otras fábricas de manufacturas (Meyer, 1980, p. 36).

Para 1910, el 55 \% de la inversión extranjera en la industria mexicana era de origen francés (Meyer, 1980, p. 33), abarcando diferentes sectores. La tabla 1 muestra el liderazgo francés en varios sectores económicos teniendo en cuenta la participación de inversión extranjera en México por país de origen. El crecimiento experimentado por los empresarios franceses les permitió construir edificios nuevos más lujosos para sus tiendas departamentales, tendencia que se mantuvo incluso después del Porfiriato y la Revolución Mexicana. Por ejemplo, al mismo tiempo que Porfirio Díaz era expulsado del país, en 1911, un grupo de grandes tiendas departamentales, de las mismas cadenas antes mencionadas, comparables con las más importantes tiendas departamentales del mundo, acababan de ser instaladas. Sus actividades fueron modernas e innovadoras, y proporcionaban una imagen de lujo, poder y belleza.

\begin{tabular}{|c|c|c|c|c|c|c|c|c|c|c|c|c|}
\hline & 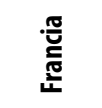 & $\%$ & 芑 & $\%$ & こ & $\%$ & 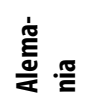 & $\%$ & 옿 & $\%$ & 홍 巳্ট兀 & $\%$ \\
\hline $\begin{array}{l}\text { Deuda } \\
\text { pública }\end{array}$ & 328.132 & 65,88 & 59.322 & 11,91 & 82.760 & 16,62 & 2.000 & 0,4 & 25.800 & 5,18 & 498.014 & 100 \\
\hline$\%$ & 36,1 & - & 1,9 & - & 8,4 & - & 3,0 & - & - & - & 14,6 & - \\
\hline $\begin{array}{l}\text { Minas y } \\
\text { metalur- } \\
\text { gia }\end{array}$ & 179.552 & 21,97 & 499.000 & 61,06 & 116.887 & 14,31 & - & - & 21.759 & 2,66 & 817.199 & 100 \\
\hline$\%$ & 19,8 & - & 38,6 & - & 11,8 & - & - & - & - & - & 24 & - \\
\hline $\begin{array}{c}\text { Vías } \\
\text { férreas }\end{array}$ & 116.240 & 10,29 & 534.683 & 47,29 & 401.396 & 35,5 & 18.720 & 1,65 & 59.506 & 5,27 & 1.130 .545 & 100 \\
\hline$\%$ & 12,8 & - & 41,4 & - & 40,6 & - & 28,5 & - & - & - & 33,2 & - \\
\hline Bancos & 99.994 & 60,28 & 34.328 & 20,69 & 17.558 & 10,59 & 12.000 & 7,24 & 2.000 & 1,2 & 165.880 & 100 \\
\hline$\%$ & 11,0 & - & 2,7 & - & 1,8 & - & 18,3 & - & - & - & 4,9 & - \\
\hline Comercio & 80.000 & 65,5 & 8.960 & 7,34 & 280 & 0,23 & - & 0 & 32.890 & 26,9 & 122.130 & 100 \\
\hline$\%$ & 8,8 & - & 0,7 & - & 0 & - & - & - & - & - & 3,6 & - \\
\hline Industria & 71.932 & 54,9 & 21.200 & 16,2 & 10.856 & 8,3 & 26.960 & 20,6 & - & 0 & 130.948 & 100 \\
\hline$\%$ & 7,9 & - & 1,6 & - & 1,1 & - & 41 & - & - & - & 3,9 & - \\
\hline $\begin{array}{l}\text { Bienes } \\
\text { raíces }\end{array}$ & 16.000 & 8,2 & 81.420 & 41,9 & 90.990 & 46,8 & 6.000 & 3,1 & - & 0 & 194.410 & 100 \\
\hline$\%$ & 1,8 & - & 6,3 & - & 9,2 & - & 9,1 & - & - & - & 5,7 & - \\
\hline $\begin{array}{l}\text { Servicios } \\
\text { públicos }\end{array}$ & 10.040 & 4,22 & 13.473 & 5,68 & 211.558 & 89 & - & 0 & 2.640 & 1,1 & 237.711 & 100 \\
\hline
\end{tabular}




\begin{tabular}{|c|c|c|c|c|c|c|c|c|c|c|c|c|}
\hline$\%$ & 1,1 & - & 1 & - & 21,4 & - & - & - & - & - & 7,0 & - \\
\hline $\begin{array}{c}\text { Combus- } \\
\text { tible }\end{array}$ & 6.800 & 6,54 & 40.000 & 38,46 & 57.200 & 55 & - & 0 & - & 0 & 104.000 & 100 \\
\hline$\%$ & 0,7 & - & 3,1 & - & 5,8 & - & - & - & - & - & 3,1 & - \\
\hline Total & 908.690 & 26,72 & 1.292 .387 & 38 & 989.485 & 29,1 & 65.680 & 1,94 & 144.146 & 4,24 & 3.400 .388 & 100 \\
\hline$\%$ & 100 & - & 100 & - & 10 & - & 100 & - & - & - & 100 & - \\
\hline
\end{tabular}

Es útil reconocer otros factores que fueron favorables para la comunidad barcelonnette en México durante su época de oro, hacia finales del siglo XIX y principios del XX. Dentro de su análisis de las instituciones, Douglas North explica que las restricciones en una sociedad se conciben como reglas formales (leyes, constituciones y derechos de propiedad) y restricciones informales (costumbres, tradiciones, tabúes, sanciones y códigos de conducta) que generalmente contribuyen a la seguridad y el orden dentro de una sociedad o mercado (North, 1989, pp. 97-112). Es decir, este autor reconoce la existencia de instituciones formales e informales en todos los aspectos que conforman una sociedad. En este sentido, es importante reconocer otras variables que jugaron un papel positivo para el desarrollo de los barcelonnettes en México y que de origen los posicionaron por encima de otros migrantes, e incluso de ciertos sectores de la población mexicana. En primer lugar, los franceses fueron particularmente bienvenidos en México durante el Porfiriato, ya que practicaban la única religión tolerada, el catolicismo. Además, eran individuos blancos de origen latino provenientes de un país con un progreso material y cultural motivo de admiración e imitación. Los franceses también se beneficiaron de otros elementos de herencia colonial, puesto que además de la intolerancia religiosa y el racismo, las colonias españolas en la región habían sido clasistas y jerarquizadas. Esto no solo les dio un estatus social privilegiado a los franceses establecidos en México, sino que mantuvo a la gran mayoría de los mexicanos fuera de la arena capitalista, salvando a los franceses de otra competencia. Algo importante por enfatizar es que la inmigración de ciudadanos franceses hacia México durante este período fue pequeña en comparación con la de inmigrantes de otros países (figura 1), por lo que esta no representó una colonización demográfica; es decir, la migración francesa en México ha sido calificada como representativa en sus logros, más que en el número de migrantes.
${ }^{*}$ Cifras expresadas en miles de pesos mexicanos.

Fuente: datos obtenidos de Turlington (1940), The Economist (Londres) y una lista aproximada de intereses franceses en México. 
Figura 1 Ciudadanos extranjeros seleccionados en México (1910)*

${ }^{*}$ Cifras en miles de personas. Fuente: INEGI (2021).

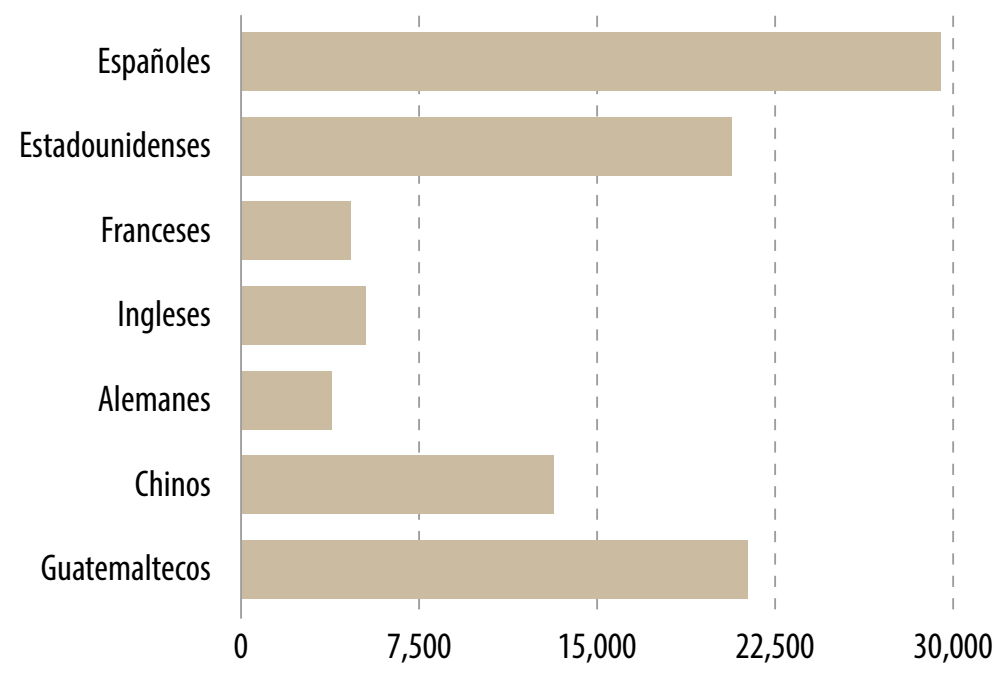

Tercera generación: el retorno a las empresas familiares

La tercera generación se centra en familias que llegaron a finales del siglo XIX y principios del siglo XX, momento en que la segunda generación se encontraba en el auge de sus negocios. Esta generación es por mucho la menos estudiada por la historiografía tradicional. Por ello, el recuento de algunas de sus características se llevará a cabo con base en la escasa información disponible.

Algunas de estas familias llegaron, se establecieron y comenzaron a trabajar, al igual que sus connacionales, con parientes u otros franceses establecidos en las principales ciudades del país. En un principio, estos trabajaron en las tiendas como empleados durante varios años. Más adelante, fueron invitados a ser socios, invirtiendo en pequeñas cantidades hasta ser propietarios y reestructurar las compañías, las cuales fueron luego administradas por miembros de sus familias. Hasta aquí, la historia es similar a la del resto de los barcelonnettes que emigraron anteriormente.

A pesar de ingresar en una época tardía, algunas empresas de miembros de la tercera generación reportaron fuertes ganancias en la última década del Porfiriato (1900-1910). Por ejemplo, Donnadieu, Veyan y Compañía obtuvo grandes ganancias entre 1900 y 1903, ya que su capital social pasó de 316.000 a 900.000 pesos, ${ }^{5}$ lo cual permitió que el capital de los socios minoritarios aumentara. Por ejemplo, la participación de los miembros de la

5 Notario Público 8 de la Ciudad de México: Ignacio Alfaro, 4 de marzo de 1903, vol. 2, escritura $1016,146-176$. 
familia Jean —una familia de la tercera generación — en esta compañía pasó de 7,2 a $36,2 \%$. Una de las principales actividades a las que se dedicaron estas familias, en un inicio, fue la industria textil, beneficiándose del mejoramiento de las vías de comunicación que se dio durante la época porfiriana, cuando las vías férreas, por ejemplo, aumentaron considerablemente, pasando de una extensión de 640 km en 1876 a 19.280 km en 1911 (SierraMoncayo, 2006, p. 264). Con esto, los empresarios ahora podrían transportar textiles a la ciudad de México y otros centros comerciales y grandes ciudades con mayor facilidad.

La década de 1920 trajo cambios importantes para la industria textil en México, algunos de los cuales afectaron al Distrito Federal, lugar donde varios barcelonnettes de tercera generación se habían establecido. Varias pequeñas empresas propiedad de árabes o judíos entraron en el campo de juego de los textiles. Las pequeñas fábricas comenzaron a crecer en las décadas siguientes, generando una verdadera competencia para los franceses y otros inversionistas del sector textil hacia la década de 1940. No obstante, durante la década de 1920 algunas familias de la tercera generación continuaron expandiendo su negocio de textiles de algodón. Además de la compra de nuevas fábricas y terrenos, algunos miembros de esta generación siguieron la tendencia general de participación francesa en el sistema bancario mexicano. Por ejemplo, fundaron la Compañía Bancaria de París y México (CBPM) en 1909. Esta compañía fusionaba, sobre todo, a miembros de la segunda y tercera generación de barcelonnettes residentes en el país (tabla 2).

\begin{tabular}{|l|c|c|}
\hline Socios CBPM & Número de acciones & Porcentaje \\
\hline J. Ollivier y Cía. & 9.770 & 9,8 \\
\hline S. Robert y Cía. & 9.770 & 9,8 \\
\hline Carlos Markassuza & 8.140 & 8,1 \\
\hline Hauser Zivy y Cía. & 6.510 & 6,5 \\
\hline Antonio Signoret & 6.510 & 6,5 \\
\hline Clemente Jacques y Cía. & 4.890 & 4,9 \\
\hline P.J. Jacques sociedad en Comandita & 4.230 & 4,2 \\
\hline Fabre Hermanos & 4.230 & 4,2 \\
\hline A. Reynaud y Cía. & 3.260 & 3,3 \\
\hline A. Richaud y Cía. & 3.260 & 3,3 \\
\hline M. Lambert y Cía. & 3.260 & 3,3 \\
\hline M. Bellon y Cía. & 3.260 & 3,3 \\
\hline
\end{tabular}

Tabla 2. Principales inversionistas de la Compañía Bancaria de París y México (1909) 


\begin{tabular}{|l|c|c|}
\hline Tardan Hermanos & 3.260 & 3,3 \\
\hline Veyan, Jean y Cía. & 3.260 & 3,3 \\
\hline J. B. Ebrard y Cía. & 3.260 & 3,3 \\
\hline Signoret, Honnorat y Cía. & 3.260 & 3,3 \\
\hline León Signoret & 3.260 & 3,3 \\
\hline Humberto Audiaguez & 3.260 & 3,3 \\
\hline José G. Escandón & 1.630 & 1,6 \\
\hline Mariano Allegre & 1.630 & 1,6 \\
\hline Abril de Greiguiel & 1.630 & 1,6 \\
\hline Hijos de Max Chauvet y Cía. & 1.630 & 1,6 \\
\hline F. Manuel y Cía. & 1.300 & 1,3 \\
\hline F. Sánchez y cía. sucesores & 1.140 & 1,1 \\
\hline Hipólito Durán & 980 & 1,0 \\
\hline Bernardo Albuneda & 970 & 1,0 \\
\hline Ailand y Cía. & 810 & 0,8 \\
\hline E. Manuel y Cía. & 650 & 0,7 \\
\hline L. Faudon y Cía. & 650 & 0,7 \\
\hline Manuel Levy & 330 & 0,3 \\
\hline
\end{tabular}

Cabe destacar que la regulación bancaria en México hacia esos años era limitada, carencia institucional que fomentó uno de los problemas más complejos de resolver en todas las regulaciones bancarias del mundo: la canalización objetiva de la captación de recursos a través de la banca para fomentar la inversión en capital físico en la economía. Compañías como la CBPM básicamente transferían la captación de recursos a sus socios a través de créditos relacionados. Es decir, los accionistas utilizaban el banco para financiar sus empresas manufactureras. La CBPM también llevó a cabo las operaciones normales de un banco comercial, recibía depósitos a la vista y depósitos a largo plazo, abría cuentas corrientes, realizaba operaciones de crédito - no solo en México, sino en otros países - y prestaba dinero a los gobiernos federales y locales. ${ }^{6}$ De hecho, existía una relación directa y, hasta cierto punto informal, entre los bancos existentes y los gobiernos federales y locales. Más adelante ahondaremos en este tema, que también requeriría de un largo proceso de pulimiento de las regulaciones bancarias para reglamentar dicha relación, buscando hacer de ella un mecanismo más objetivo para la canalización de recursos. 
Algunas de las compañías que fundaron las familias de esta tercera generación se dedicaron a actividades distintas a las de sus connacionales, como explotar concesiones de agua para la producción y venta de energía eléctrica. Para el siglo XIX, empresas como la Compañía Industrial de Orizaba S.A. (CIDOSA), en Veracruz, San Ildefonso, en la Ciudad de México, y la Compañía Industrial Atlixco, en Puebla, construyeron sus propias plantas hidroeléctricas para abastecer sus fábricas. Sin embargo, la venta y provisión de electricidad a otras fábricas distintas a las propias representó un importante negocio adicional para los miembros de esta tercera generación, uno que los distingue de las compañías propiedad de barcelonnettes fundadas anteriormente. Estos empresarios suministraban energía a diferentes regiones del sur de la Ciudad de México, incluyendo San Ángel, Mixcoac, Tlalpan y Coyoacán. En 1904, Sébastien Robert, junto con otros barcelonnettes de tercera generación, fundó la compañía energética La Luz Eléctrica. Además, en 1909, su empresa S. Robert y Compañía Sucesores se asoció con Veyán, Jean y Compañía, otra empresa de la tercera generación, y con Noriega y Compañía, formando la Compañía Hidroeléctrica del Río de la Alameda S.A. ${ }^{7}$

Después de muchos años de trabajar principalmente en textiles, finanzas y la generación de energía eléctrica, algunos miembros de la tercera generación de barcelonnettes crearon un negocio en el sector de la construcción y la vivienda que se caracterizó por ser diferente a los tradicionales. Muchos multifamiliares fueron creados por estos empresarios, quienes hacia la década de 1940 fraccionaron los terrenos donde se ubicaban sus naves industriales una vez que el negocio textil allí ubicado comenzó a debilitarse, sobre todo por la competencia con árabes y judíos antes mencionada.

Por ejemplo, en 1925, la familia Jean comenzó una urbanización conocida como La Concepción, ubicada al suroeste de la Ciudad de México en los ranchos Anzaldo y Contreras, los cuales fueron divididos en varios bloques y lotes. ${ }^{8}$ Además, a finales de 1920 , esta familia creó dos nuevas empresas en la Ciudad de México, La Compañía Explotadora y Realizadora de Bienes Raíces S.A. (1927) y La Inmobiliaria Comercial S.A. (1929), con el objetivo de expandir su negocio inmobiliario. ${ }^{9}$ A fines de la década de 1930 , los Jean

\footnotetext{
Notaria Publica 5 de la Ciudad de México: 1909, pp. 17-25.

8 Notario público 56 de la Ciudad de México: Eduardo Chico, 15 de mayo de 1931, vol. 63, escritura fallida $5468,71$.

9 Notario Público 56 de la Ciudad de México: Eduardo Chico, 17 de agosto de 1929, vol. 51, escritura $4666,65-73 ;$ y, abril 27, 1938, vol. 97, escritura 8268, 232-62.
} 
habían construido tres nuevas urbanizaciones en la misma región de la Ciudad de México, los fraccionamientos Padierna, El Molinito y Guadalupe. ${ }^{10}$

La expansión de los Jean en el negocio de la vivienda se vio favorecida por las conexiones políticas que estos tenían, además de que la Ley de Planificación y Zonificación, publicada en el Diario Oficial en 1936, incorporó al sector privado en la planeación urbana del Distrito Federal "buscando resolver los problemas, hasta entonces exclusivos de la administración" (Hernández, 2008, pp. 194-195). Dicha ley tenía la intención de atender problemas de vivienda resultado del gran crecimiento poblacional de la ciudad, además de crear una Comisión Planeadora del Distrito Federal apoyada por una Comisión Mixta que incluía empresarios distinguidos y miembros del sector bancario, quienes intervendrían en el financiamiento de la construcción (Hernández, 2008, p. 195). Banamex fue una de esas compañías bancarias. Desde la adquisición del CBPM por parte de Banamex, en 1930, los Jean se involucraron en las operaciones como socios, lo que permitió que les otorgaran permisos para construir incluso en áreas sobrepobladas y sin los servicios básicos requeridos. Sergio Valerio Ulloa también encontró barcelonnettes de tercera generación que se involucraron en el sector inmobiliario de Guadalajara. Estos empezaron fraccionando y vendiendo tierras y construyendo viviendas a principios del siglo $X X$, fundando firmas como La Compañía Jalisciense de Construcciones, la cual comenzó a operar hacia principios del siglo XX, y la Compañía de Fomento y Bienes Raíces en Guadalajara, en 1910 (Valerio, 2015, pp. 284-287).

Con la evidencia disponible, es posible afirmar que las compañías constructoras de bienes raíces de algunos barcelonnettes de la tercera generación crecieron en Ciudad de México, Puebla, el Estado de México y la ciudad de Guadalajara. A través de los años, la tercera generación manejó los riesgos de su actividad económica ante la inestabilidad política del país de una forma interesante: diversificando sus posesiones geográficamente para evitar ser vulnerables a un solo hombre fuerte regional impredecible, haciendo inversiones riesgosas cuando otros capitalistas estaban vendiendo activos con descuento, como fue el caso de Puebla en los años 20 y 30 del siglo pasado, y diversificando sus negocios, no solo en diferentes regiones sino en nuevos sectores económicos, como los mencionados anteriormente.

10 Notario Público 33 de la Ciudad de México: Daniel García, 30 de septiembre de 1930, vols. 77 y 79, escrituras 5627 y 5629, 117-29 y 138-54. Notario Público 56 de la Ciudad de México: Eduardo Chico, mayo de 1938, vol. 98, escritura 8283, 260-67. 


\section{LA EVOLUCIÓN DE LA EMPRESA BARCELONNETTE: LOS CAMBIOS ESTRATÉGICOS FUNDAMENTALES ENTRE LA SEGUNDA Y LA TERCERA GENERACIÓN}

En las compañías con participación de empresarios de la tercera generación se observó una centralización cada vez mayor hacia el control de estas a manos de los miembros de sus familias, lo que se dio a través del crecimiento de su propiedad accionaria en las compañías en las que originalmente comenzaron participando como socios minoritarios. Esta estrategia de control familiar les dio a las empresas una mayor adaptabilidad y flexibilidad para la toma de decisiones ante el inestable entorno político de México de la primera mitad del siglo XX. De hecho, la investigación sobre la estructura organizativa, la evolución y el cambio en las empresas, según resumen Sharma et al. (1997, p. 15), sugiere que las empresas que se mantienen bajo el control de la familia son "menos diferenciadas horizontalmente y más dependientes de los controles informales [...]. Como resultado, la empresa familiar puede tener más éxito en negocios que requieren una estructura ágil y receptiva". Esta característica ayudó a la tercera generación a lidiar de una mejor forma con el débil entorno institucional al que se enfrentaron cuando iniciaron sus actividades. También les dio la capacidad de crecer igual o por encima de las tasas de sus competidores, así como responder con eficacia a eventos externos como la Revolución Mexicana y sus consecuencias, como la reforma agraria.

Por su parte, en su análisis sobre negocios familiares en México, RamírezSolís et al. (2017, p. 567) afirman que una de las características que define a las empresas familiares en América Latina es que estas suelen consistir en carteras de múltiples negocios con inversiones en varias actividades, a menudo sin sinergias entre ellas. Este rasgo aplica directamente a los miembros de la tercera generación de barcelonnettes en México, quienes diversificaron su cartera de negocios muchas veces sin relacionarse entre ellos.

A su vez, los miembros de la tercera generación disfrutaron de los beneficios de pertenecer a una gran red social que conservaban por sus relaciones con otros franceses. Esta red comenzó a incluir a individuos de otras nacionalidades que penetraban cada vez más la muy cerrada red inicial barcelonnette. Este aspecto tuvo beneficios evidentes, por ejemplo, en la posibilidad de hacer negocios en lugares donde era difícil avanzar, como en Puebla, y en la forma en que sus empresas obtenían crédito a través de su participación en el sector bancario en compañías como la CBPM, 
Tabla 3. Grandes compañías textiles de México (1912) en la que colaboraban miembros de la segunda y tercera generación de barcelonnettes vinculados a través de la red social común.

La tercera generación y sus fábricas no han atraído tanta investigación académica como CIDOSA y CIVSA, los consorcios franceses más grandes de la segunda generación, en parte porque se expandieron más discretamente que los demás productores provenientes de Barcelonnette, lo cual explica por qué escaparon de las depredaciones de los políticos revolucionarios. Es importante destacar que los barcelonnettes de la segunda generación se habían expandido inicialmente, creando compañías familiares. No obstante, con los años empezaron a asociar sus compañías en los sectores textil y comercial con otras grandes empresas, formando así grandes consorcios compuestos por socios franceses y, en ocasiones, españoles. Su asociación con otras compañías les permitía controlar muchas fábricas textiles y tiendas departamentales a la vez, sacrificando la flexibilidad en las decisiones que consorcios de esta naturaleza pueden manejar. Este tipo de asociación se puede observar en la tabla 3.

\begin{tabular}{|c|c|c|c|c|}
\hline Compañía & $\begin{array}{c}\text { Año de } \\
\text { fundación }\end{array}$ & Fábricas textiles & Tiendas & Socios \\
\hline $\begin{array}{c}\text { Compañía } \\
\text { Industrial de } \\
\text { Orizaba S. A. (CIDOSA) }\end{array}$ & 1889 & $\begin{array}{l}\text { Cerritos } \\
\text { Cocolapan } \\
\text { San Lorenzo } \\
\text { Río Blanco }\end{array}$ & $\begin{array}{l}\text { El Palacio de Hierro } \\
\text { El Puerto de Liverpool } \\
\text { La Ciudad de Londres } \\
\text { El Gran Oriental } \\
\text { El Puerto de Veracruz } \\
\text { El Correo Francés }\end{array}$ & $\begin{array}{l}\text { Tomás Braniff; J. Ollivier y Cía.; J. B. Ebrard y Cía.; J. Tron y Cía.; } \\
\text { Signoret, Honnorat y Cía.; Lambert, Reynaud y Cía.; } \\
\text { Garcin, Faudon y Cía.; Juan Quinn. }\end{array}$ \\
\hline $\begin{array}{l}\text { Compañía } \\
\text { Industrial } \\
\text { Veracruzana S. A. } \\
\text { (CIVSA) }\end{array}$ & 1896 & $\begin{array}{l}\text { Santa Rosa } \\
\text { El León }\end{array}$ & $\begin{array}{l}\text { Las Fábricas Universales } \\
\text { La Ciudad de México } \\
\text { El Centro Mercantil } \\
\text { La Reforma del comercio }\end{array}$ & $\begin{array}{l}\text { A. Reynaud y Cía.; S. Robert y Cía.; F. Manuel y Cía.; } \\
\text { P. y J. Jacques y Cía.; Paulino Richaud. }\end{array}$ \\
\hline $\begin{array}{l}\text { Compañía } \\
\text { Industrial de San } \\
\text { Antonio Abad S. A. }\end{array}$ & 1892 & $\begin{array}{l}\text { San Antonio Abad } \\
\text { La Colmena } \\
\text { Barrón Miraflores }\end{array}$ & La Reforma del Comercio & $\begin{array}{l}\text { Î́nigo Noriega; Adolfo Prieto; Agustín Garcin; } \\
\text { Enrique Mojardín. }\end{array}$ \\
\hline $\begin{array}{l}\text { Compañía Industrial de } \\
\text { Atlixco S. A. }\end{array}$ & 1902 & Metepec & La Reforma del Comercio & $\begin{array}{l}\text { B. Rovés y Cía.; A. Richaud y Cía.; S. de Juanbelz y Cía.; } \\
\text { Solana Barreneche Cía.; Antonio Basagoiti; Luis Barroso Arias; } \\
\text { Agustín Garcin; Leopoldo Gavito; Félix Manino; Benjamín } \\
\text { Oncins; Iñigo y Constantino Noriega; Sotero de Juanbelz; } \\
\text { Emilio André; Eduardo Vega y Santiago Aréchaga. }\end{array}$ \\
\hline
\end{tabular}




\begin{tabular}{|c|c|c|c|c|}
\hline $\begin{array}{c}\text { Compañía } \\
\text { Industrial } \\
\text { Manufacturera } \\
\text { S. A. }\end{array}$ & - & $\begin{array}{c}\text { Hércules } \\
\text { San Antonio } \\
\text { La Purísima } \\
\text { La Sultana } \\
\text { La Teja } \\
\text { Río Grande }\end{array}$ & $\begin{array}{l}\text { Las Fábricas Universales } \\
\text { La Reforma del Comercio } \\
\text { La Ciudad de Londres } \\
\text { (Guadalajara) }\end{array}$ & $\begin{array}{l}\text { Agustín Garcin; Joseph Signoret; Brun; Lerdo de Tejada; } \\
\text { Cuzin, Fortuol Bec; Lèbre y Cía. }\end{array}$ \\
\hline $\begin{array}{c}\text { Compañía } \\
\text { Industrial de } \\
\text { Jalisco/ Compañía } \\
\text { Industrial de } \\
\text { Guadalajara S. A. }\end{array}$ & 1899 & $\begin{array}{l}\text { Río Blanco (Jalisco) } \\
\text { Atemajac } \\
\text { La Escoba }\end{array}$ & $\begin{array}{l}\text { La Ciudad de Londres } \\
\text { (Guadalajara) } \\
\text { Las Fábricas de Francia } \\
\text { (Guadalajara) }\end{array}$ & $\begin{array}{l}\text { Fortoul Chapuy y Cía; Gas y Cía.; Laurens Brun y Cía.; } \\
\text { Bellon Agorreca y Cía.; E. Lèbre y Cía. }\end{array}$ \\
\hline $\begin{array}{l}\text { Compañía } \\
\text { Industrial de San } \\
\text { Ildelfonso S. A. }\end{array}$ & - & San Ildelfonso & El Puerto de Liverpool & J. B. Ebrard; H. Reynaud; E. Pugibet. \\
\hline Veyan Jean y Cía. (VJC) & 1898 & $\begin{array}{l}\text { La Magdalena } \\
\text { Santa Teresa }\end{array}$ & La Francia Marítima & $\begin{array}{l}\text { Socios en 1912: Luis Veyan; Adrián Jean; Camilo Jean; } \\
\text { Alfonso Jean; } \\
\text { León Meyran (sin voz ni voto). }\end{array}$ \\
\hline
\end{tabular}

La tercera generación se distinguió de los barcelonnettes de la segunda por adquirir gradualmente casi todo el capital de las empresas en las que originalmente habían sido socios secundarios, ampliando así su influencia y las actividades de las empresas. Considerando que los barcelonnettes de la generación anterior típicamente crearon grandes consorcios que comprenden compañías individuales asociadas, los de la tercera generación aseguraron que la asociación a la compañía se restringiera a individuos, generalmente miembros de su misma familia, como se puede observar en el último caso presentado en la tabla 3, el de Veyan Jean y Cía. (VJC). Es decir, los grandes consorcios corporativos de la segunda generación, compuestos por varias compañías propiedad de familias barcelonnettes, agregaron muchas fábricas textiles y tiendas departamentales simultáneamente. Sin embargo, las familias de la tercera generación no se asociaron en estos consorcios. Estas familias, en general, mantenían múltiples negocios familiares que variaban la composición de sus miembros pero siempre tenían una fuerte presencia familiar. Bajo esta estructura, lograron construir importantes riquezas en México, algunas del tamaño de las de sus compatriotas, y en sectores en ocasiones diferenciados de sus connacionales, como es el caso de su participación en la generación de energía eléctrica o en el negocio de la construcción. En entrevista a Minouche Suberville, fundadora de la asociación Raíces Francesas en México, ella afirma que, en efecto, los
Fuente: elaboración propia con base en información del notario público y Gómez-Galvarriato (2008). 
últimos barcelonnettes en llegar al país han sido poco estudiados, tuvieron estrategias empresariales diferentes a sus connacionales, exploraron otros sectores económicos y, cuando tuvieron la oportunidad, mantuvieron su cercanía con el régimen político. El siguiente apartado profundiza en este último punto.

\section{CAPITALISMO DE AMIGOS, CONTRIBUCIÓN A LA EMPRESA BARCELONNETTE}

Además de los beneficios que obtuvieron los franceses por el hecho de ser franceses, explicados en los apartados anteriores, y de las diferentes exitosas estrategias aplicadas por cada una de las generaciones, otros aspectos ayudaron a algunos barcelonnettes a construir fortunas. Nos referimos al capitalismo de amigos, término empleado para describir una economía en la que el éxito en los negocios depende de las relaciones cercanas entre políticos y empresarios. Cabe aclarar que las redes han estado presentes en la actividad económica durante toda la historia de la humanidad, y que el modelo económico capitalista no es la excepción. Sin embargo, las redes pueden tener efectos específicos no deseados en aquellas economías donde la elaboración y el ejercicio de normatividades adecuadas puede tener un efecto que limita los aspectos nocivos de las mismas. Esto también aplica para el tema del capitalismo. Varios estudiosos de este modelo económico han concluido que todo el capitalismo es de amigos. Sin embargo, la adecuada regulación y aplicación de este puede contener efectos nocivos.

Retomando el tema de la institucionalidad formal e informal estudiada por North, México, tanto en los siglos pasados como en el actual, se ha caracterizado por ser un país de instituciones formales débiles. Esto ha llevado a la creación de redes de negocios informales para compensar la falta de solidez institucional y los riesgos derivados de ello. Estas redes, sin embargo, terminan operando en favor de pequeños grupos de poder compuestos por unos cuantos empresarios y políticos, quienes, protegiendo sus intereses individuales, han contribuido a mantener un desarrollo institucional débil a través de los años, generando así un círculo vicioso.

Estas características, aunque presentes en México desde tiempos coloniales, han prevalecido desde el fortalecimiento del modelo capitalista durante el Porfiriato (1876-1911), manteniéndose a pesar de la inestabilidad política que surgió de la Revolución (1910-1920), con lo cual se 
demuestra que ningún cambio significativo ocurrió entre los individuos que habían controlado específicamente el sector industrial durante el Porfiriato. Muchos de los mismos industriales continuaron disfrutando de condiciones favorables por varias décadas. Por ejemplo, después de la Gran Depresión de 1929, las élites industriales tradicionales se recuperaron en la década de 1930 y prosperaron durante y después de la Segunda Guerra Mundial -a pesar de la eventual participación de nuevos actores-, estableciendo vínculos con la élite política surgida de la revolución mexicana, que en 1929 fundaría el partido político que años luego se transformaría en el Partido Revolucionario Institucional (PRI).

Antes del Porfiriato, el México Independiente era definido, en general, por el poco control que tenía el Estado sobre las fuerzas productivas, el desorden social, el caos político y una marcada regionalización. Además, el país independiente heredó una sociedad altamente jerárquica y segmentada. Como resultado, la formación de una infraestructura económica sólida y productiva sería un proceso complicado y tenso. El creciente proceso de creación de nuevas plantas industriales no tuvo lugar hasta que el Porfiriato estableció control sobre el territorio del país, sentando con ello las bases para la acción económica. Parte de ese control fue resultado de la creación de alianzas y redes con hombres fuertes locales ${ }^{11}$ y con empresarios. La inversión extranjera jugó también un papel importante en la administración de Díaz, por lo que ocasionalmente los inversionistas extranjeros se asentaron en México para manejar sus proyectos nuevos. De este modo, estos inmigrantes comenzaron a formar parte de la élite económica mexicana. Este fue el caso para la comunidad barcelonnette.

De acuerdo con varios estudios, elaborados en su mayoría por neoinstitucionalistas, durante el Porfiriato y los años revolucionarios la élite industrial tradicional disfrutó de favores del gobierno a través de mecanismos tales como alianzas de integración política vertical (IPV), las cuales les permitieron sobrevivir e incluso crecer bajo nuevas condiciones de incertidumbre en el marco institucional (tanto formal como informal). Además, compañías relacionadas con los bancos habían reducido los riesgos de quiebra e incorporado menos cambios en su propiedad. Al mismo tiempo, los banqueros se prestaron mutuamente dinero (préstamos al interior) y los bancos otorgaron créditos de largo plazo a individuos y compañías asociadas con miembros de sus juntas directivas. En palabras de

11 Personas influyentes desde lo popular, lo político o lo económico, o los tres. 
Maurer: "las firmas con el crecimiento más rápido no eran las mejores, sino las mejor conectadas" (Maurer, 2002, p. 15). Estos autopréstamos, evidentemente, fueron permitidos por una falta de regulación bancaria sólida, lo que empezaría a cambiar apenas hacia finales del siglo pasado.

La concentración de bancos y firmas controlados por redes cerradas de negocios en todo el país permitieron la formación de monopolios típicos del Porfiriato. Comercio, finanzas, tierra y manufactura estuvieron concentrados en unas pocas manos. Las personas que controlaban la economía también controlaban el sistema político, así que no hubo incentivos para romper los monopolios creados.

La industria textil del algodón tenía un tipo diferente de organización industrial, puesto que existían muchas compañías operando en los mercados locales, regionales y nacionales. Algunas de ellas conservaron las características de pequeñas firmas administradas familiarmente, mientras que otras crecieron más y se convirtieron en grandes consorcios compuestos por compañías individuales. Sin embargo, los megaconsorcios textiles de propiedad barcelonnette, CIVSA y CIDOSA, reclamaron casi toda la producción de bienes de alta calidad y alrededor del $20 \%$ del resto de la producción nacional (Haber, 1989, p. 44).

La red de barcelonnettes había construido vínculos principalmente con funcionarios públicos, sobre todo en el sector bancario; las consecuencias de este vínculo bancario fueron profundas. Las conexiones con los proveedores de capital explican la distorsión y la concentración de múltiples mercados en manos de pocos proveedores de bienes, fortaleciendo la estructura monopolística del aparato productivo y el capitalismo de amigos. Un claro ejemplo de esto fue la creación de la Ley General de Instituciones de Crédito de 1897 por el gobierno federal, junto con los pocos bancos que existían en el momento. Esta ley limitaba la entrada de nuevos participantes en la arena bancaria, lo que llevó a un muy concentrado sector bancario y, al mismo tiempo, a una industria altamente concentrada con características monopólicas. Este es un punto particularmente importante, porque era precisamente la falta de capital financiero el elemento crucial que dio surgimiento al capitalismo de amigos en los orígenes del capitalismo. En otras palabras, la necesidad de los gobiernos de tener acceso a recursos financieros llevó a la formación de redes sociales entre políticos y banqueros, que a su vez dio beneficios monetarios a individuos de ambos lados. En el caso mexicano, como resultado de esta ley que institucionalizó prácticas previas, 
los banqueros continuaron disfrutando ganancias monopólicas debido a la limitación de participantes y de oficiales de gobierno en el sector, agentes que decidían quién recibiría una carta bancaria, usualmente canjeada por "un asiento en la mesa y cantidades sustanciales de valores" (Maurer, 2002, p. 41). Así, la concentración de industrias fue el resultado de las múltiples firmas conectadas a bancos, que recibían crédito vía prácticas de préstamos internos ya mencionadas.

Por otra parte, aunque algunas compañías bancarias administradas por barcelonnettes de tercera generación a finales del Porfiriato y durante la Revolución se jactaban de no haber tenido ninguna relación con Porfirio Díaz, muchos de sus miembros directivos tenían relaciones cercanas con gobernadores porfiristas o políticos cercanos a Díaz; por ejemplo, José Yves Limantour, ministro de Finanzas. Además, las familias de la tercera generación forjaron nuevas relaciones con políticos revolucionarios. De hecho, en una carta fechada el 26 de enero de 1912, Scherer, un financiero de origen francés de la época, informa a Limantour, mientras este último estaba exiliado en Francia, sobre la intención del nuevo gobierno de crear una empresa de construcción para llevar a cabo los contratos de casi todas las obras públicas planeadas en el país en conjunto con la CBPM:

Esta semana he estado buscando suscripciones ${ }^{12}$ para una nueva Compañía Nacional Mexicana de Construcciones, que actualmente se está formando, con un capital de dos millones, y cuyo consejo de administración está integrado por: Gustavo Madero, hermano del presidente Francisco I. Madero; el cuñado de Madero, Gabriel Escalante; y Néstor Pino Suárez, hermano del vicepresidente [...]", entre otros socios. ${ }^{13}$

Así, durante la primera mitad del siglo XX, observamos la relación benéfica de empresarios de origen barcelonnette con el Estado, ya que se logró superar las debilidades del marco institucional mexicano y alcanzar una estabilidad política y económica, que no se había logrado durante el siglo XIX, lo cual permitió a varios inmigrantes barcelonnettes crear diferentes negocios. En términos económicos, el efecto del capitalismo de amigos se refleja, en parte, en el privilegio de unos pocos empresarios capaces de operar sus negocios como monopolios. Sin embargo, en el mediano y largo

12 "Suscripciones" se refiere al proceso de los inversionistas que se registran y se comprometen a invertir en un instrumento financiero, antes del cierre real de la compra; las acciones son la representación del capital pagado o invertido en el negocio.

13 Centro de Estudios de Historia de México Carso (CEHM-Carso). Colección José Y. Limantour, Fondo CDLIV, 1880-1934, enero 26, 1912. 
plazo (hasta el presente), el capitalismo de amigos, que previamente había resuelto las debilidades institucionales, limitó profundamente la construcción y evolución de las instituciones formales, incluida la de un sistema legal sólido, manteniéndolos débiles y secuestrados en beneficio de unos pocos individuos hasta el presente. Esto fenómeno es lo que el autor de este documento ha definido como la paradoja del capitalismo de amigos: aunque en un inicio las relaciones entre políticos y empresarios contribuyeron a la estabilidad política y económica del país ante un entorno institucional débil, posteriormente estas mismas redes contribuirían a que las instituciones formales se mantuvieran débiles hasta la actualidad.

\section{CONCLUSIONES}

Al estudiar el éxito económico de los barcelonnettes en México, como ejemplos de inmigrantes empresarios, hemos analizado el contexto que los benefició y las estrategias empresariales que estos aplicaron durante tres generaciones, además de otros aspectos que también permitieron su desarrollo, como el capitalismo de amigos.

Las familias barcelonnettes que emigraron a México se elevaron de posiciones humildes, como propietarios de cajones de ropa, a la prominencia en la industria textil y la banca, diversificándose con el tiempo hacia otros negocios. Sin embargo, se evidencian diferencias importantes en las estrategias empresariales de estos empresarios entre las tres generaciones.

La primera generación representa el origen de la riqueza a través de la construcción de un conjunto de cajones de ropa por medio de una red cerrada, compuesta casi enteramente por inmigrantes franceses. La segunda generación representa la época de oro de los barcelonnettes en México, donde tuvo lugar la construcción de grandes consorcios empresariales que manejaban principalmente fábricas, bancos y tiendas departamentales. Finalmente, la tercera generación tuvo que volver a la estrategia de empresa familiar e incursionó en muchos sectores económicos, lo que les permitió mantenerse dentro de la élite económica del país a través de estrategias más flexibles, ante el entorno de inestabilidad política y social que resurge en México desde la primera década del siglo XX. Por ejemplo, las familias de la tercera generación mantuvieron su negocio textil dentro de la familia y no participaron en grandes empresas textiles, como CIDOSA y CIVSA, creadas 
por barcelonnettes de la segunda generación. A pesar de evitar grandes consorcios, estos mantuvieron una posición muy importante en el negocio textil de México. Además, la diversificación de la tercera generación en los sectores de la generación de energía hidroeléctrica y la construcción, fueron actividades comerciales no exploradas por otros barcelonnettes.

Después de la tercera generación no es posible hablar de una cuarta, debido a que el grueso de los barcelonnettes que aún están presentes en el país comenzaron a mezclarse con el resto de la sociedad mexicana, tanto en términos de socios de negocios como formando familias con individuos de origen mexicano, diluyendo las características distintivas de las estrategias vinculadas a su nacionalidad. A pesar de ello, hoy en día todavía suenan en los medios del país noticias vinculadas a apellidos barcelonnettes de una élite ya mezclada pero que se mantiene. Por ejemplo, apellidos como Ebrard, Jean o Suberville se mantienen vigentes.

Finalmente, en este artículo se aclaró el tema de la existencia de redes comerciales y de negocios en toda la historia de la humanidad, reconociendo la presencia del capitalismo de amigos desde el inicio del capitalismo mundial, o lo que es lo mismo, la relaciones estrechas en los negocios entre políticos y empresarios. Además, se profundizó en el análisis de estos temas para comprender el desarrollo de los barcelonnettes en México. Así, podemos mencionar que para el caso mexicano, en general, y de estos empresarios, en particular, el estudio del capitalismo de amigos permite definir la paradoja del mismo nombre: si en un inicio las relaciones entre políticos y empresarios contribuyeron a la estabilidad política y económica del país durante el Porfiriato, como respuesta a un entorno institucional débil, posteriormente estas mismas redes de políticos y empresarios contribuirían a que las instituciones formales se mantuvieran débiles hasta la actualidad.

Una característica distintiva del capitalismo de amigos actual es que dificulta la cohesión e integridad de las instituciones. En México, las instituciones potencialmente sólidas a menudo se debilitan en el Congreso, por ejemplo, donde se aprueban leyes que apoyan los intereses de diferentes individuos de la élite del poder. El funcionamiento cotidiano de las instituciones formales también puede verse comprometido con la ruptura o el incumplimiento de las regulaciones, según lo dictado por la élite del poder. Estos son solo dos de los muchos mecanismos empleados para evitar el uso adecuado de las instituciones formales en un país donde violar la ley rara vez tiene consecuencias, especialmente para las personas privilegiadas. 


\section{REFERENCIAS}

\section{Archivo material}

Archivo Histórico Banamex, Ciudad de México, México.

Archivo General de Notarías de la Ciudad de México. Gobierno del Distrito Federal, Ciudad de México, México.

Notario Público 5 de la Ciudad de México: Bernardo Cornejo.

Notario Público 33 de la Ciudad de México: Daniel García.

Notario Público 56 de la Ciudad de México: Eduardo Chico.

Notario Público 8 de la Ciudad de México: Ignacio Alfaro.

Centro de Estudios de Historia de México, Carso (CEHD-Carso). Colección José Y. Limantour.

\section{Entrevistas}

Michel Jean, entrevista del autor. Ciudad de México, 11 de septiembre de 2001.

Minouche Suberville, entrevista del autor. Ciudad de México, 18 de julio de 2012.

\section{Referencias bibliográficas}

Bátiz, J. A. (2005). El archivo histórico Banamex: su génesis. América Latina en la Historia Económica, 23, 95-104. https://doi.org/10.18232/alhe. v12i1.356

Béraud, G. (2008). Centinelas del pasado: del cajón de ropa a las tiendasancla. En L. Gamboa-Ojeda (ed.), Los Barcelonnettes en México: miradas regionales, siglos XIX-XX (pp. 247-273). Benemérita Universidad Autónoma de Puebla.

Canudas, E. (2005). Las venas de plata en la historia de México. Síntesis de historia económica del siglo XIX. Editorial Utopía/Universidad Juárez Autónoma de Tabasco.

D’Anglade, J. L. (2012). Un gran patrón Barcelonnette en México: Joseph Ollivier y su familia, 1850-1932 (Leticia Gamboa Ojeda, trad.). ABZAC.

Echanove, C. A. (1974). Manual del extranjero. Porrúa.

Galán, E. (2010). Estrategias y redes de los empresarios textiles de la compañía industrial Orizaba 1889-1930 (tesis doctoral, Universidad Veracruzana, Xalapa, México). Repositorio Institucional Universidad Veracruzana. 
Gómez-Galvarriato, A. (2008). Los Barcelonnettes y la modernización de la comercialización y de la producción de textiles en el Porfiriato. En L. Gamboa-Ojeda (ed.), Los Barcelonnettes en México: miradas regionales, siglos XIX-XX, (pp. 195-196). Benemérita Universidad Autónoma de Puebla.

Gouy, P. (1980). Peregrinations des barcelonnettes au Mexique. Universitaries de Grenoble.

Grupo Eleuterio Quintanilla (2021, febrero 12). La historia de la humanidad es la historia de las migraciones. https://www.equintanilla.com/ documentos/viaje/libro2000/C1/c1.htm

Haber, S. (1989). Industry and underdevelopment: The Industrialization of Mexico 1890-1940. Stanford University Press.

Hernández, R. (2008). El Distrito Federal: historia y vicisitudes de una invención. Instituto Mora.

Instituto Nacional de Estadística y Geografía [INEGI]. (2021, febrero 12). Censo de población y vivienda 1910. INEGI. https://www.inegi.org.mx/ programas/ccpv/1910/

Kenny, M., García-Acosta, V., Icazuriaga-Montes, C., Suárez-Argüello, C. E., \& Artís-Espriu, G. (1979). Inmigrantes y refugiados españoles en México: siglo XX. Centro de Investigaciones Superiores del Instituto Nacional de Antropología e Historia.

Maurer, N. (2002). The power and the money: The Mexican financial system, 1876-1932. Stanford University Press.

North, D. C. (1991). Institutions. Journal of Economic Perspectives, 5(1), 97112. https://doi.org/10.1257/jep.5.1.97

Meyer, J. (1980). Los franceses en México durante el siglo XIX (Pastora Rodríguez, trad.). Relaciones, 1(2), 5-54.

Ramírez-Solís, E. R., Baños-Monroy, V. I., \& Rodríguez-Aceves, L. A. (2017). Family business in Latin America: The case of Mexico. En F. W. Kellermanns \& F. Hoy (eds.), The Routledge companion to family business (pp. 567-579). Routledge.

Sharma, P., James C., \& Chua J. (1997). Strategic management of the family business: Past research and future challenges. Family Business Review, 10(1), 1-36. https://doi.org/10.1111/j.1741-6248.1997.00001.x 
Sierra-Moncayo, M. J. (2006). Atlas histórico de México. ITAM.

Turlington, E. (1940). Foreign investments in Mexico. Annals of the American Academy of Political and Social Science, 208, 103-111. https://doi. org/10.1177/000271624020800111

Valerio, S. (2015). Los Barcelonnettes en Guadalajara, siglos XIX y XX. Universidad de Guadalajara/Instituto Mora-Conacyt. 